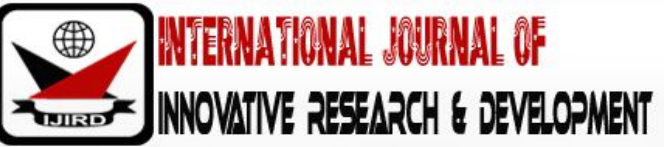

ISSN 2278 - 0211 (Online)

\section{Understanding Culture, Embedded Values, and Development in Northern Nigeria}

\author{
Dr. Aisha Ibrahim Ningi \\ Lecturer, Department of History, Yobe State University Damaturu, Nigeria
}

\begin{abstract}
:
This review paper focuses on the definitions and roles of culture, values and their hidden effects on development in Northern Nigeria. Trends have indicated that culture is one primary basis of individual's initial preparation to life in most societies. While values are considered to be deeper than beliefs, are determinant of attitudes, and ultimately, at least in part predict one's behavior. In Northern Nigeria, there is a change in values. The paper, therefore, identifies a subset of negative cultural value that is primarily responsible for the under-development of the region. Findings have unraveled that the rampant case of girl-child involvement in street hawking at the detriment of their education is no longer a practice, but a value that has been nurtured, and sustained, and the effect of which holds back sustainable development in the North. The paper concludes that one cannot talk of any meaningful development without girls' right to education.
\end{abstract}

Keywords: Culture, values, development, girl-child Education

\section{Introduction}

There is no doubt that societal development and growth is the concern of every country and Nigeria, in general, is not an exception. Such a development aims at improvement in individual's quality of life and progress in all aspects of human endeavours. Northern Nigeria in particular, is a multi-cultural and multi-ethnic society and most populous when compared to the south and eastern regions of the country (NDHS, 2014). Specifically, girls and women constitute about eighty-two million of the total population. The literacy rate is forty-two percent even though it was a result from baseline survey focussing only on western education. Therefore, any discussion about development in the country in general and indeed Northern Nigeria in particular most necessarily entails consideration for these group of people; the role they play; and the barriers they face in developing the future. However, because culture shapes experiences and influences societal development, girls and women are mostly viewed as underprivileged in many ways. So, it seems necessary that societal attachment to culture and values be studied in the light of how they militate against development. Thus, the main objectives of this paper is to explore the roles played by culture and values as guiding principles in the lives of the majority of the people of Northern Nigeria and a hindrance to achieving sustainable development (SDG, 2015). This is because, the girl-child and women have a major role to play in the development of the country at large.

The question arises as to what determines development in a society; what prevalent notions and beliefs are held by the people; do the people's socio-cultural values in any way determine the process and progress of development in a country? Do the values held by the people of Northern Nigeria enhance or pose a hindrance to its growth and development? Obviously, there are important intellectual differences in opinions between those think that cultural conditions and values held by a people shape societal development and those who believe that educational development determines society and culture. The debate takes place in both economic and social history. It would have been entirely understandable if the cultural Anthropologists or Ethnographers proclaim the dominance of cultural aspect over development. However, what is more striking as Aslam (2009) pinpoints is that E.E. Hagen, a distinguished economist, has been won over the position that change in cultural personality is the basic explanatory variable in societal development (Aslam, 2009). Thus, the relevance of culture and values at the individual level can best be understood in terms of development. The stronger the modern values of individuals in a society the more the development will be. While the primordial the societal values are the weaker the development process (Kinelev, 1997).

In order to understand the values that shaped the behaviour of any group of people in their dealings with one another within the society, it is important to first know the meaning(s) of culture so dominant or mainstream which is passed down from one generation to another. Even though culture is a fragile phenomenon, it is widely regarded as a powerful tool for human survival. Thus, it is apt to say that culture is the identity of the people or rather is something that unites people just as it is the way of life of a people. Thus, if a person loses their culture, the societal values would definitely be contaminated. This is similar to the current development in Northern Nigeria because the cultural values have been misplaced which has paved ways to so many innovations within the society (Hosen, Khandoker, \& Islam, 2010; Dantata, 2005). 


\subsection{Perspectives on Culture}

It is also important to remember that culture being a multi-dimensional concept offered different meaning to different people (Carpenter, 2000; Elliott, 1994). Partly in reaction to this usage, the definition of culture initiated in the book of a British anthropologist Tylor referred to it as any feature that influences people within social groups as though could be arranged in a developmental range right through the wildness to civilization as cited by (Avruch, 2000). However, it is worthy of note that in the 19th century, the greater part of the hurdles in terms of explanations and understanding stemmed from the way the term has been used numerously. For instance, some authors believed Tailor's definition is worth quoting in its entirety in two ways. First, because it was the foundational base for an anthropological stand and second, because, it comparatively explained the reason for subsequent authors like Avruch (2000); Triandis (1994); and Trompenaars \& Hampden-Turner (2004) to have found definitional efficiency in their writings about culture. Yet, some noted that another usage of culture advanced in anthropological works of Matsumoto (1996) though his writings have its roots in the writings of (Schein, 1984 \& 1990).

In this regard, a well-defined position has been offered which encapsulates all behavioral patterns shared by a group of people, although viewed differently for each individual, but most often transferred to subsequent generations (Matsumoto, 1996). In the same vein, the observable trend from the opinion of Marsella, Dubanoski, Hamada, \& Morse (2000) offered an outstanding and vivid review of the history of culture. They demonstrated that culture was used in three ways, all of which could be found in today's as well. According to them, culture referred to special intellectual endeavors in which at present people might refer to as the 'high' culture which is different from the 'popular' culture that was used previously. The definition above, therefore, sounds as if only a portion of the typically small social group has a culture. In a related development, Hofstede (2001) came up with a historical standpoint to some of the ways in which the term culture has been construed. Thus, this definition of culture could be linked more to aesthetics rather than the humanities and social sciences (Avruch, 2000). However, some other writers believed people should not distinguish low culture from high culture, just as people should not draw a line between them. This could be seen as in relation to the earlier definition given by Tylor as mentioned by Avruch (2000). Even though, Tylor's definition is in contrast to Avruch's view in which the later, reiterated that all societies require culture, which they must acquire by virtue of associations with the social group. In essence, culture is made up of knowledge, habits, and to the capabilities. Thus, the uniqueness of Tylor's explanation continued for quite long. This has been the main purpose for most experts in politics to be fascinated and felt it was essential to delineate their relevant cultural domain of political culture in the mid-1950.

In another development, culture has been defined as a treasure that is part of people's collective memory, memories, and perception of themselves (Spencer-Oatey, 2008). Therefore, such experiences included those images and their interpretations or meanings transmitted from past generations, from contemporaries, or formed by individuals themselves. Whereas, Smith \& Bond (1996) established that culture in a way consists of both explicit and implicit patterns of behaviour acquired and transmitted by either by symbols, which constitutes the distinctive achievements of human groups, or their embodiment in artifacts and other objects. Based on the above, the essence of culture consists of selected olden ideas and traditions which are historically derived by attaching values. So, the cultural systems may, on the one hand, be considered as products of action, or as conditional elements of future action within a given society. Similarly, a number of inquiries were carried out about the culture in which it has been established that it is like an iceberg which could be fragmented into external and internal levels (Weaver, 2001; Hanley, 1999; \& Cohen, 1997). As the iceberg is submerged what ordinarily remained is the tip of the iceberg which is the external and smallest part. So it is within this smallest part of a culture that the behavior of the people could be seen easily. This means that under such situation, for example, people might be overly concerned about matters related to wearing the correct or wrong clothes, and greeting people correctly or incorrectly. On the other side of the spectrum, however, the internal is the greatest part of a culture, mostly regarded as underneath the water level. This also means that the largest part of a person's culture is within it. This tends to suggest that culture is inside people's heads and most importantly contained the values and views unconsciously learned while growing up in a particular culture. In essence, such value includes people's way of thinking and perceiving which determine most behavior within the individual society. Importantly, an individual's acceptance and perception of the internal culture as significant values helped them to acquire a sound structure for interpreting and analyzing behavior (Halstead, 2005).

Therefore, there might be likely three layers of culture that are part of societal learned behavior patterns and perceptions (Scheins, 1990). According to him, those who share a similar culture in most cases, do so because they imbibed it or acquired it as they were raised by individual members of the society who have it. The most obvious is the body of cultural traditions that distinguish certain specific society and this form the first layer. In addition, the second layer of culture is a subculture which normally identifies an individual within a particular social organization. In other words, individuals have a shared subcultural identity that is reinforced through their language, and other traditions. While, the third layer of culture is the conglomeration learned behavior patterns are shared by all humanity collectively and generally referred to as cultural universe (Schein, 1990). Thus, a close scrutiny of this aspect is that no matter where people live in the world, they share these universal traits. Examples of such human cultural traits include using age and gender to classify people (e.g., teenager, senior citizen, woman, man), distinguishing between good and bad behaviour, raising children in some sort of family setting, classifying people based on marriage and decent relationships and having kinship terms to refer to them (e.g., wife, mother, uncle, cousin) among others (Weaver, 2002; Triandis, 2000; Avruch, 2000; \& Schein, 1990). Specifically, in a diverse and complex society in which there exists a large conglomeration of people from many different parts of the social background, they often retain much of their original cultural traditions. Though, such a group of people is likely to be part of an identifiable subculture in their new society (Hanley, 1999). 
Furthermore, Henry Triandis (2002) talked about human beings and the material culture aspect of their culture as the tangible part of the environment. So, it is worthy of note that even recent evidence suggests that culture and society are not the same (Matsumoto, 1996). He observed that cultures are complexes of learned behavior patterns and perceptions which made Triandi's explanations weak. The argument here is that societies are groups of interacting organisms because the people are not the only animals that have societies (Abbas, 2003). So, in the case of humans, the societies are groups of people who directly or indirectly interact with each other. Also, people in human societies generally perceive that their society is distinct from other societies in terms of shared traditions and expectations. However, culture could be said to be dynamic and never static because it is constantly changing and easily lost because it exists only in the minds of individuals. Similarly, some researchers also said that culture is "us" because "we" make it; we shape it as we love it to be (Schein, 1990). So, the more "we" know about the cultures of others, the more tolerant, open-minded, and global "we" become. Even though our cultural traits, values, and beliefs are different and diverse, however, it is the understanding and respects people foster that make them truly human (Ogbu, 1988).

In order to analyze why people in a particular social setting behave the way they do, it is important to look for the values that govern behavior, which is part of the second layer (Schein, 1990). However, in identifying such values, people or group members within a given society, it is usually noted as they represented accurately only the manifest or espoused values of a culture. That is to say, they focus on what people say is the reason for their behavior, what they ideally would like those reasons to be, and as well as what is often their rationalizations for their behavior. Yet, the underlying reasons for their behavior remain concealed or unconscious (Halstead, 2005). Thus, to really understand a culture and to ascertain more completely the group's values, it is imperative to delve into the underlying expectations which are typically insensible, but which actually determine how group members perceive, feel and think (Schein, 1990). Hence, such expectations have themselves learned responses that originated as adopted values. Likewise, value leads to behavior, and as that behavior begins to solve the problem which prompted it in the first place, the value gradually is transformed into an underlying notion or assumption about how things really are. As such, the notion or assumption drops out of awareness because it is increasingly taken for granted. Therefore, such "taken-for-granted expectations" are so powerful in the sense that they are less debatable than the adopted values. In other words, the domain of values can be divided into (1) ultimate, non-debatable taken-for-granted values, for which the term 'notions or assumptions' is more appropriate; and (2) debatable, adopted, for which the term values are more applicable. In stating that basic notions or assumptions are unconscious, the researcher is not arguing that this is a result of repression. Thus, culture is the acquired pair of glasses through which a group of people sees life. In essence, it is a call for individuals to agree upon some common values that bind them in harmony.

The standpoints above has sometimes been claimed to provide a useful way of resolving disputes over values in culturally plural societies like Northern Nigeria. While on the other hand, is the notion of collectivism a situation in which it is a very tight social framework and the "we" is highlighted. In other words, this kind of values applies to everywhere and at all time. On this view, certain human actions are always right or always wrong, irrespective of circumstance. The values in this sense are subjective, though it varies across individuals and cultures, and are in many ways aligned with beliefs and belief systems (Haydon, 2004). This type of values includes doctrinal or ideological (religious, political, social, ethnic, moral, and aesthetic values). This definition is open to criticism on the grounds that it fails to differentiate quite distinct things like convictions, virtues, and commitments and that it treats values as a kind of possession, something which people have. It is true that to talk about the value of something one has always been to talk of its worth, and that when a society value something that particular society is making a high estimate of its worth (Haydon, 2004). However, the term values seem to be used to refer to the criteria by which a group of people or society make such value judgments, to the principles on which the value judgments are based (Halstead \& Tylor, 1996). So, despite a long epoch of resolves to adequately define the term 'culture', up till the early 1990s, there was no agreement among Anthropologists regarding its precise meaning. Moreover, even though people often mistake culture with mere dancing and singing, culture is much more than that, as it relates to the ideology of a particular group of people.

Lastly, the above-mentioned studies highlight culture as the patterns of ideas being created by man within a social setting. In addition, the various perspectives and definitions of culture offer how societal values plunge under the subjective part of the individual's culture which is normally intertwined with 'religion' (Ningi, 2012). Thus, this part of the culture is all about how a group of people perceives the social environment, how they perceive the notion of self, the social norms, the material lust, and the educational framework among others. In the case of values, it is the foundational base in gauging honor. People's basic values served as symbols of behavior which recognized anything good or bad.

\subsection{Perspectiveson Values}

Values have been studied in various disciplines such as moral philosophy, history, business ethics, behavioral economics, corporate governance, political science, among others. So, to better understand the nature and the influence of societal values, there is the need to find the meaning attached to values. Historically, several reviews on cultural, moral, and social values were carried out over the years (Halstead \& Taylor, 2005). Yet, much disagreement still exists about the term values. In this regard, Halstead \& Taylor (2005) questioned what are values? They observed that values may be defined as enduring prescriptive principles that are specified within a particular structure.

As Aslam (2009) puts it, values identify the factors that must be considered when making a decision in order for the decision to be perceived as just. Also, values held can seemingly determine the behavior and attitude of human beings and can be a contributing factor towards the development process of a given country in a significant manner. Similarly, it is imperative to point out that some writers have attempted to draw distinctions between societal values from one place to the other. Therefore, the term values could be well-defined as far-reaching affection regarding suitable passages of 
exploits within a particular society. In the same vein, values are being described as overall attitudes, and principles a person is honored and keen to openly uphold. Likewise, values are generally seen and considered as ideas, assurances, and worth. In other words, values are worth, preferred dutifully from other choices and used continually (Sharma, 2010). This implies that it is hard for individual groups of people to make a decision when they know what their values are. Consequently, values identified the factors that must be considered when taking a decision in order for the decision to be perceived as just and desirable (Elliott \& Willmes, 2012).

In such situations, it can be said that each person tries to justify his or her behaviors, attitudes, liking, and disliking based on the values of the society with which one belongs. Thus, values are ethical ideas and beliefs as it is the values that people hold which decide about their preferences in particular situations. As such, values reveal what needs to be done and a person's sense of right and wrong (Carr \& Landon, 1993). In addition, values are the characteristics every individual has which is being carried every single day, which helps one makes decisions, makes choices, etc. Hence, everything that runs life are values or rather the core of how people make decisions in life are some of the valuable elements of those groups of people. Other socio-cultural settings provide values that covered the preservation of custom in society (Hargreaves, 1994). These values set restrictions though people might pursue other alternatives. Moreover, some society's offers a standard of consciousness much more of an intellectual portion which further offers the basic foundation for social behavior (Halstead, 2005).

In a related development, the evaluation of values entails the whole actions and beliefs that are carefully allied to peculiar identity and integrity. So, one way of understanding the concept of values is through dimensions of variation in cultural values (Halstead \& Tylor, 1996). In the African context in general and Nigeria in particular, the family connection is highly preferred and expected. Thus, values are preferences and the tendencies individuals have in their lives and instilled in an individual's earlier stage of life. It tells people what is important or rather what is valuable in that culture (Elliott \& Willmes, 2012). In other words, it is the values that people hold which decide about their preferences in particular situations and therefore called for a clear distinction to be made here. For instance, as a consequent upon that is, whether a person's educational structure has an adverse effect. This is so because if the system gives provision for adjustments towards change, and those people would have reason to value change. Accordingly, every human society has tended to have some mechanisms as populations that may support or dissuade shift with their values (Haydon, 2004). However, Ladan (2009) observed that the larger the inhabitants of a particular society, the more multifaceted and even problematic its basic values would become. Thus, socio-cultural values are things that are prized or of benefit to a particular group of individuals within a society (Halstead \& Taylor, 1996).

\subsection{Cultureand Value Element as Factors That Impedes Development}

Until recently, both culture and inherent values were not tied to societal development. Though, there has been observable changes over the years on some societal values and their implication towards national development. Consequently, some of the values held by the people of Northern Nigeria and incorporate into their daily lives pose a hindrance to development and progress. Girl-child education is still lagging behind, and it is the single most vital tool with the immense power to transform; the people do not generally accept girl-child education because of the influence of culture and strong attachment to negative values, as well as a misconception of religion. Similarly, the people's socio-cultural values have to a large extent has slow down the development process of the northern region. In particular, one deep-rooted cultural value has found greatness among the majority of the people is girl-child involvement in street hawking (Umar, 2012). This value element has been considered an accommodated norm even as detrimental as it is and as a form of child labor it is. Even though it's been seen as 'lucrative' but with a price (ILO, 2013; Davis, 2012).

\section{Summary}

The paper summed up that societal culture usually seen as a manifestation or a demonstration of a multifaceted whole cuddles understanding, and any other experiences acquired by man in a given environment. While values are foundational base in gauging honor, about how the people have learned to think how things ought to be or how people ought to behave. At present, people's basic values served as symbols of behavior which recognized anything good or bad. These values set restrictions though people might pursue other alternatives. Thus, culture and sustained value elements are some of the power factor(s) that have a direct effect and also shakes development in Northern Nigeria.

\section{Conclusion}

With all that has been discussed, the concluding part of this paper uncovered one major impediment towards development in Northern Nigeria. This has to do with strict adherence to negative socio-cultural value as girl-child involvement in street hawking at the expense of their education.

\section{References}

i. Abbas, T. (2003). The Impact of Religio-cultural Norms and Values on the Education of Young South Asian Women. British Journal of Sociology of Education, 8(2), 411-428.

ii. Aslam, M. (2009). Education gender gaps in Pakistan: Is the labour market to blame. Economic Development and Cultural Change, 57 (4), 747-784.

iii. Avruch K. (2000). Culture and negotiation pedagogy. Negotiation Journal, 16 (4), 339-346

iv. Bond, M. H., \& Smith, P. B. (1996). Cross-cultural social and organizational psychology. Annual review of psychology, 47(1), 205-235. 
v. Carpenter, S. (2000). Effects of cultural tightness and collectivism on self-concept and causal attributions. Cross-Cultural Research, 34(1), 38-56.

vi. Carr, D. \& Landon, J. (1993). Values in and for Education at 14+, New York: Routledge.

vii. Cohen, R. (1997). Negotiating across cultures: International communication in an interdependent world. US institute of Peace Press.

viii. Cummings, W. (2001). Modern primitivism: the recent history of civilization's discontents. Critical Studies, 15(1), 297316.

ix. Dantata, F. (2005). Acceleration of the Girl-Child Education in Northern Nigeria. Kano Journal of Educational Studies KAJEST Department of Education, Bayero University Kano, 3(1), 8-12.

x. $\quad$ Davis, J. (2012). Study of Street Hawkers in Ghana' s Capital. Journal of African Studies, 51(3), 32-37.

xi. Elliott, K. C., \& Willmes, D. (2013). Cognitive attitudes and values in science. Philosophy of Science, 80(5), 807-817.

xii. Halstead, J. M., \& Taylor, M. J. (1996). Values in education and education in values. Psychology Press.

xiii. Halstead, J., \&Taylor, M. J. (2005). Values in Education and Educational in Values. London: The Falmer Press.

xiv. Handwerker, W. P. (2002). The construct validity of cultures: Cultural diversity, culture theory, and a method for ethnography. American Anthropologist, 104(1), 106-122.

xv. Hanley, J. (1999). Beyond the tip of the iceberg: Five stages toward cultural competence. Reaching today's youth. 3 (2), 9-12.

xvi. Hargreaves, A. (1994). Development and desire: A postmodern perspective. New York: Teachers College Press

xvii. Hartley, D. (2009). Education policy, distributed leadership and socio-cultural theory. Educational Review, 61(2), 139150.

xviii. Haydon, G. (2004). Values education: sustaining the ethical environment. Journal of Moral Education, 33(2), 115-129.

xix. Hofstede, G. (2001). Culture's Consequences. Comparing Values, Behaviours, Institutions, and Organizations across Nations. London: Sage.

xx. Hosen, M., Khandoker, M. S. H., \& Islam, S. M. (2010). Child labour and child education in Bangladesh: Issues, consequences and involvements. International Business Research, 3(2) 1-8.

xxi. International Labour Organizations. (2013). Marking progress against child labour, Global estatimates and trends 20002013. Geneva: Jasmin Merdan.

xxii. Kinelev, V. (1997). Education and civilization. Prospects, 27(3), 371-383.

xxiii. Ladan, H. (2009). Education in Nigeria: A Retrospective. Daily Trust, August, p14. Kano, Nigeria

xxiv. Mahon, L. (2010). Hawkers: An Ethnographic Study of Strategies of Survival. New York: Fielding Graduate University.

xxv. Matsumoto, D. (1996). Culture and Psychology. California: Brooks/ Cole.

xxvi. Ningi, A. (2012). Girl-child Education: Challenges for Sustainable Development in Northern Nigeria. Proceedings of Economics Development 111-114.

xxvii. Ogbu, J. U. (1988). Cultural diversity and human development. New Directions for Child and Adolescent Development, 1988(42), 11-28.

xxviii. Sachs, J. D. (2012). From millennium development goals to sustainable development goals. The Lancet, 379 (9832), 2206-2211.

xxix. Sagar, A. (1998). The human development index: a critical review. Ecological Economics, 25((3),), 249-264.

xxx. Schein, E. (1984) Coming to a new awareness of organizational culture. Sloan Management Review 25(2), 3-16.

xxxi. Schein, E. (1990) Organizational culture. American Psychologist 45(2), 109-119.

xxxii. Sharma, R. (2010). Cultural-historical perspectives on teacher education and development, British Journal of Educational Technology, 41(3), 112-112.

xxxiii. Sinkula, J. M., Baker, W. E., \& Noordewier, T. (1997). A framework for market-based organizational learning: Linking values, knowledge, and behaviour.Journal of the academy of Marketing Science, 25 (4), 305-318.

xxxiv. Spencer-Oatey, H. (2008). Culturally Speaking Second Edition: Culture, Communication and Politeness Theory. Bloomsbury Publishing.

xxxv. Sperber D. (1996). Explaining Culture: A Naturalistic Approach. Oxford: Blackwell

xxxvi. Sustainable Development Goals (2015). Beyond 2015: Education for the Future, Nigerian Review.

xxxvii. The Nigeria Demographic and Health Survey (NDHS) (2014). Country Review.

xxxviii. Triandis, H. C. (1994). Culture and social behavior. Mcgraw-Hill Book Company.

xxxix. Triandis, H. C. (2000). Dialectics between cultural and cross-cultural psychology. Asian Journal of Social Psychology, 3(3), 185-195.

xl. Triandis, H. C., \& Suh, E. M. (2002). Cultural influences on personality. Annual review of psychology, 53(1), 133-160.

xli. Triandis, H. C., Carnevale, P., Gelfand, M., Robert, C., Wasti, A., Probst, T., \& Kim, U. (2001). Culture, personality and deception: A multilevel approach. International Journal of Cross-Cultural Management, 1, 73-90

xlii. Trompenaars F. \& Hampden-Turner, C. (2004). Managing People Across Cultures, Chichester: Capstone Publishing Limited

xliii. Umar, F. (2012). Street Hawking: Oppressing the Girl Child or Family Economic Supplement? Journal of Sustainable Development, 2 (1), 169-175.

xliv. UNESCO, (2004). Gender outcomes in Education: why are girls still held back? Education for all: Global Report.

xlv. Weaver, G. (2001). Ethics programs in global businesses: Culture's role in managing ethics. Journal of Business Ethics, 30 (1), 3-15. 